\title{
Fisher Grading Scale and Cognitive Deficits - Literature Review
}

\section{Escala de Fisher e déficits cognitivos - Revisão da literatura}

\author{
Moysés L. Ponte Souza ${ }^{1,2}$ Ana C. Vieira ${ }^{2}$ Hildo R.C. Azevedo-Filho ${ }^{1,2}$ \\ 1 Universidade de Pernanbuco, Recife, PE, Brazil \\ ${ }^{2}$ Hospital da Restauração, Recife, PE, Brazil \\ Address for correspondence Moyses Souza, MD, Ms, PhD, \\ Universidade de Pernambuco, Recife, PE, Brazil \\ Arq Bras Neurocir 2020;39(4):279-283. \\ (e-mail: souzamoyses@hotmail.com).
}

\begin{abstract}
Keywords

- intracranial aneurysm

- cognitive dysfunction

- subarachnoid hemorrhage

- tomography
\end{abstract}

\section{Resumo \\ Palavras-chave \\ - aneurisma intracraniano \\ - disfunção cognitiva \\ - hemorragia subaracnóidea \\ - tomografia}

Subarachnoid hemorrhage (SAH) accounts for 5 to $10 \%$ of all types of stroke, with rupture of brain aneurysms being related to deficits in memory, executive functions, and language. Changes in brain functions appear to be related to the presence of blood in the subarachnoid space, and the Fisher Scale (FS) correlates the amount of blood identified on computed tomography (CT). This paper presents a literature review of the association of FS with cognitive deficits secondary to aneurysmal subarachnoid hemorrhage (aSAH), using PubMed. The attempt to correlate the amount of blood identified in the CT with the development of cognitive alterations presents conflicting data. It was evidenced that some of the studies did not perform cognitive tests, or did not show differences between the scores of FS due to sample difficulty. The FS, even with its limitations and imperfections, seems to be a safe and easily reproducible way to predict neurological, cognitive or neuropsychological deficits, in view of its routine use when analyzing patients with aSAH.

Hemorragia subaracnóidea (HSA) representa de 5 a $10 \%$ de todos os tipos de acidente vascular encefálico, estando a ruptura de aneurismas cerebrais relacionada a déficits na memória, nas funções executivas e na linguagem. As alterações nas funções cerebrais parecem estar relacionadas à presença de sangue no espaço subaracnóideo, sendo a escala de Fisher (EF) a forma de mensuração do conteúdo hemático, realizada através de tomografia computadorizada (TC). O presente artigo apresenta uma revisão da literatura sobre a associação da EF com déficits cognitivos secundários a HSA aneurismática ( $\mathrm{HSAa}$ ), tendo como banco de dados para a pesquisa o PubMed. A tentativa de correlacionar a quantidade de sangue identificada na TC de crânio com o desenvolvimento de alterações cognitivas apresenta dados bastante conflitantes, evidenciando que alguns dos trabalhos não realizaram testes cognitivos, ou não demonstraram diferenças entre os graus da EF por dificuldade na amostragem. A EF, mesmo com suas limitações e imperfeições, parece ser uma forma segura e de fácil reprodutibilidade para predizer déficits neurológicos, cognitivos ou neuropsicológicos, tendo em vista o seu uso rotineiro na análise de pacientes com HSAa. received

June 26, 2017

accepted

August 24, 2017
DOI https://doi.org/

10.1055/s-0037-1606632. ISSN 0103-5355.
Copyright $(2020$ by Thieme Revinter

Publicações Ltda, Rio de Janeiro, Brazil
License terms

(요 (1) $\Theta \circledast$ 


\section{Introduction}

Subarachnoid hemorrhage (HSA) represents 5 to $10 \%$ of all types of cerebrovascular accidents, affecting mainly women in the $5^{\text {th }}$ decade of life. ${ }^{1,2}$

The main surgical treatment options for cerebral aneurysms are microsurgery with clipping and the endovascular technique with embolization, using microcoils. Both aim to occlude the aneurysm, preventing the rebleeding and reducing the risk of complications. ${ }^{3}$

A review of the literature (61 studies) on cognitive evaluation and functional outcome of patients with aneurysmatic HSA (HSAa) revealed important deficits in memory (ranging from 14 to 61\%), in executive functions (ranging from 3 to $76 \%$ ), and in language (ranging from zero to $76 \%)^{4}$

Alteration in brain functions seem to be related to the presence of blood in the subarachnoid space. ${ }^{5}$ The Fisher scale (FS) is the form of measurement of the hematic content, performed through computerized tomography (CT), which is the most used exam in neurosurgical practice. ${ }^{6}$

\section{Methodology}

The present article presents a review of the literature on the association of FS with cognitive deficits secondary to HSAa. The bibliographic references were accessed in the PubMed database, using the following keywords: Fisher scale, Fisher grade, subarachnoid hemorrhage, cognitive impairment, neuropsychological assessment, intracranial aneurysm and outcome, with articles published in the last 20 years (1997-2016).

Thus, the present article aims to discuss aspects related to cognitive alterations and FS, performing a thorough analysis of the selected studies, and not focusing specifically in neuropsychological tests in the present review.

\section{Fisher Scale, Modified Fisher and Claassen}

The FS subdivides patients with HSAa into four groups (-Table 1), according to the distribution and amount of blood observed at CT performed after rupture of a cerebral aneurysm.

Despite being a globally widespread scale, the FS has several limitations: patients with higher scores do not have a higher risk of developing vasospasm, due to the greater involvement of Fisher $3^{6}$; it doesn't make the separation between patients with

Table 1 Fisher Scale for Aneurysmal Subarachnoid Hemorrhage

\begin{tabular}{|l|l|}
\hline Score & Description \\
\hline Fisher 1 & No subarachnoid blood detected \\
\hline Fisher 2 & $\begin{array}{l}\text { Diffuse bleeding with all }<1 \text {-mm thickness } \\
\text { vertical layers (interhemispheric fissure, } \\
\text { insular cisterna, cisterna ambiens) }\end{array}$ \\
\hline Fisher 3 & $\begin{array}{l}\text { Localized clot (defined as } 3 \times 5 \text { mm) or } \\
\text { bleeding with 1-mm thickness vertical layer }\end{array}$ \\
\hline Fisher 4 & $\begin{array}{l}\text { Intraventricular or intraparenchymatous clot, } \\
\text { with or without diffuse subarachnoid } \\
\text { hemorrhage. }\end{array}$ \\
\hline
\end{tabular}

cisternal HSA and intraventricular hemorrhage, a relevant factor for the development of vasospasm ${ }^{7-9}$; and it doesn't take into account the density and clearance rate of the clot. ${ }^{10,11}$

When we compared the FS with the modified Fisher ${ }^{12}$ and Claassen scales, ${ }^{8}$ we noticed an important difference in the absence of blood. In the FS, absence of blood is classified as Fisher 1, because this scale does not have a zero score, unlike the other two most current scales.

Another important disparity is the evaluation of intraventricular hemorrhage, considered Fisher 4 on the original scale. It may correspond to modified Fisher 2 or 4, depending on the thickness of the HSA. ${ }^{12}$

The Claassen scale ${ }^{8}$ differentiates the involvement of both lateral ventricles or of only one of them, a fact not specified in the FS and modified Fisher. The presence of blood in the lateral ventricles (especially when it occurs bilaterally), but not in the $3^{\text {rd }}$ or $4^{\text {th }}$ ventricles, represents an important predictor of vasospasm. ${ }^{8}$

For these reasons, Kramer et $\mathrm{al}^{13}$ compared the FS, the modified Fisher and the Claassen scales, evaluating the development of vasospasm and late infarction, evidencing that the increase in scores has a linear relationship in the last two, and that the FS Fisher 3 score is related to a higher incidence of vasospasm (35\%).

In terms of mortality, $18 \%$ of patients with HSAa evolve to in-hospital death, the main causes being the direct effects of initial hemorrhage (55\%) and of the aneurysm rebleeding (17\%). As predictors of this mortality, we found: modified Fisher, age of the patient, presence of loss of consciousness in the ictus, Glasgow scale on admission, and size of the aneurysm. ${ }^{14}$

In relation to mortality after rebleeding, it is known that it is associated with higher scores of modified Fisher, as well as larger aneurysms and with worse assessments on the Glasgow scale after the new bleeding. ${ }^{15}$

Fisher scale and vasospasm/late cerebral infarction may be defined as a deterioration caused by vasospasm and/or an infarction related to vasospasm evidenced in CT that was not observed on admission or in the immediate postoperative CT. ${ }^{8}$

Approximately 60 to $70 \%$ of the patients with HSAa present with radiological vasospasm, two thirds of which present severe ischemic events that cause transient or permanent neurological deficits, configuring clinical or symptomatic vasospasm. ${ }^{16}$

Fisher et $\mathrm{al}^{6}$ developed the main study that relates the location and amount of blood in the subarachnoid space with vasospasm development, finding a statistically significant correlation for Fisher 3 score (92\% sensitivity, 95\% specificity, 96\% positive predictive value and $91 \%$ negative predictive value). ${ }^{6}$

The results of Hütter et al, ${ }^{17}$ when comparing patients with minimal/mild HSAa (Fisher 1 and Fisher 2) with patients with moderate/severe HSAa (Fisher 3 and Fisher 4), showed that those with higher bleeding had worse assessments in relation to quality of life.

Considering that the presence of intraparenchymal blood and the hemoventriculum confers an additional risk to vasospasm development, it was proposed to create a new Fisher score $3+4$, combining massive cisternal hemorrhage with 
intraventricular or intraparenchymal hematoma $>5 \mathrm{~mL}$. Thus, the presence of vasospasm in $40 \%$ of the cases of Fisher 3 and in $68 \%$ of the Fisher $3+4$ was evidenced. ${ }^{18}$

In recent years, the concept of clot clearance rate has emerged, and can be defined as the difference between the initial and final volumes of the clot (in $\mathrm{mL}$ ), divided by the number of days ${ }^{11}$; or through the residual volume of the clot, which is the percentage between the measurements of the initial evaluation of the bleeding in relation to the analyses over the days after the HSAa. ${ }^{19}$

The lower the clot clearance rate, Fisher 3 score, the higher initial clot volume and the higher initial clot density correlate with the risk of developing vasospasm in univariate analyses. However, only the highest initial volume of the clot and the lowest daily clearance rate remain with statistical significance in multivariate analyses. ${ }^{11}$

However, only the highest initial bleeding volume is associated with late cerebral infarction, when measurements of each cistern, ventricle, parenchyma or groove near the cortex are used. ${ }^{19}$

Vasospasm development differs between patients undergoing microsurgical clipping and those undergoing endovascular treatment. Initially, both groups present perianeurysmatic spasm, with a distal progression only in microcoil-treated patients. ${ }^{20}$

Approximately $86 \%$ of the patients with delayed cerebral infarction had moderate or severe neuropsychological deficits. The presence of ischemia is associated with a higher propensity (6.38 times) for the development of cognitive sequelae, when compared with patients with and without late cerebral infarction. ${ }^{21}$

\section{Fisher Scale and Cognitive Alterations}

The attempt to correlate the amount of blood identified in the cranial CT with the development of cognitive alterations in patients with HSA secondary to the rupture of cerebral aneurysms presents very conflicting data (-Table 2$)^{6}$

Kreiter et $\mathrm{al}^{22}$ showed that the presence of blood in the interhemispheric fissure and in the sylvian fissure was related to a higher cognitive decline, although it did not demonstrate that higher scores were associated with cogni- tive alterations, using the method pursued by Hijdra et $\mathrm{al}^{23}$ that graduates the hematic densities in 10 cisterns/fissures and in the 4 ventricles.

Similarly, Caeiro et $\mathrm{a}^{24}$ showed that the hematic density was not associated with neuropsychiatric disorders.

The FS was considered the most important factor related to language dysfunction in patients with anterior circulation aneurysm rupture. ${ }^{25}$

The neuropsychological evaluation (depression test) in patients with HSAa showed greater involvement in cases with anterior communicating artery aneurysm rupture, when compared with other locations, not being evidenced greater impairment of higher FS scores. ${ }^{26}$ However, when evaluating the sample of this study, it was observed that $100 \%$ of the patients had FS scores 3 or 4 .

Wong et $\mathrm{al}^{27}$ demonstrated that $73 \%$ of the patients presented cognitive decline, when the Montreal Cognitive Assessment was used after 3 months of HSAa, with late cerebral infarction being the main risk factor. However, when analyzing our data, it is evident that $100 \%$ of the patients had FS scores 3 or 4 , a result that precludes the association between the FS and cognitive deficits.

Sheldon et al ${ }^{28}$ showed a significant difference in working memory among patients with HSAa and individuals considered normal. However, it was not possible to differentiate between the various degrees of the FS, probably due to the small sample of patients with HSAa $(n=21)$. Comparing neuropsychological assessments in 3 groups of patients (HSAa, incidental aneurysms or perimesencephalic hemorrhage), it is evident that $78 \%$ of the patients with aneurysmatic HSA had scores 1 or 2 on the Fisher scale, with no difference in groups classified according to the FS. ${ }^{29}$

Literature reports indicate that $96 \%$ of patients with ischemia had a FS score of 3 or 4, with higher scores of this scale associated with 4.34 times greater propensity to the presence of neuropsychological alterations in univariate analysis, a fact not proven in multivariate analysis. ${ }^{21}$

When care tests were performed in patients with HSAa, it was observed that $58 \%$ of these presented alterations, although they had 4-5 scores in the Glasgow Outcome Scale (GOS). The FS evaluation, performed through the median, showed no

Table 2 List of Articles Relating the Fisher's Scale (Fisher et $\mathrm{al}^{6}$ ) with Cognitive or Neuropsychological Assessments

\begin{tabular}{|l|l|l|l|l|l|l|}
\hline Autors & Publication & $\begin{array}{l}\text { Number } \\
\text { of cases }\end{array}$ & $\begin{array}{l}\text { Fisher } \\
\mathbf{1}+\mathbf{2}\end{array}$ & $\begin{array}{l}\text { Fisher } \\
\mathbf{3}+\mathbf{4}\end{array}$ & Criteria & Relation \\
\hline Fisher et al $(1980)^{6}$ & Neurosurgery & 47 & $38.3 \%$ & $61.7 \%$ & Vasospasm & + \\
\hline Hütter et al (1998) & Neurosurgery & 51 & $22 \%$ & $78 \%$ & $\begin{array}{l}\text { Memory/ } \\
\text { attention }\end{array}$ & + \\
\hline Yoo et al $(2011)^{26}$ & Ann Rehabil Med & 20 & - & $100 \%$ & Depression & - \\
\hline Wong et al $(2012)^{27}$ & J Neurol Neurosurg Psychiatry & 90 & - & $100 \%$ & Cognition & - \\
\hline Sheldon et al $(2013)^{28}$ & J Neurol Sci & 21 & Not related & Not related & Memory & - \\
\hline Krajewski et al $(2014)^{29}$ & Neurosurgical Review & 27 & $78 \%$ & $22 \%$ & Cognition & - \\
\hline Stienen et al $(2014)^{21}$ & World Neurosurg & 92 & $28 \%$ & $72 \%$ & Cognition & + \\
\hline Wallmark et al $(2015)^{30}$ & Stroke & 19 & Not related & Not related & Attention & - \\
\hline de Souza et al $(2015)^{31}$ & World Neurosurg & 185 & $39.5 \%$ & $60.5 \%$ & Language & + \\
\hline
\end{tabular}


statistical difference between patients with attention disorder and those considered normal, both with score $3 .{ }^{30}$ Our research group correlated the various degrees of the FS with language alterations in individuals with HSAa secondary to rupture of the anterior circulation aneurysm in the period preceding the treatment, evidencing that the groups of patients with Fisher 3 and Fisher 4 presented worse scores in all assessments performed. ${ }^{31}$

\section{Conclusion}

Because it is a pathology with high incidence in the population, the study of factors associated with a better outcome after rupture of a cerebral aneurysm is widely debated in the literature.

Several studies have sought to correlate the various degrees of the FS with cognitive alterations in individuals with HSAa. However, some of these studies did not undergo cognitive tests, or did not show differences between the FS grades by sampling difficulties.

The FS, even with its limitations and imperfections, seems to be a safe and easily reproducible way to predict neurological, cognitive or neuropsychological deficits, in view of its routine use in the analysis of patients with HSAa.

\section{Conflict of Interests}

The authors have no conflict of interests to declare.

\section{References}

1 Clinchot DM, Bogner JA, Kaplan PE. Cerebral aneurysms: analysis of rehabilitation outcomes. Arch Phys Med Rehabil 1997;78(04): 346-349

2 Dombovy ML, Drew-Cates J, Serdans R. Recovery and rehabilitation following subarachnoid haemorrhage: Part II. Long-term follow-up. Brain Inj 1998;12(10):887-894

3 Fraser JF, Riina H, Mitra N, Gobin YP, Simon AS, Stieg PE. Treatment of ruptured intracranial aneurysms: looking to the past to register the future. Neurosurgery 2006;59(06):1157-1166, discussion 1166-1167

4 Al-Khindi T, Macdonald RL, Schweizer TA. Cognitive and functional outcome after aneurysmal subarachnoid hemorrhage. Stroke 2010;41(08):e519-e536

5 Sonesson B, Säveland H, Ljunggren B, Brandt L. Cognitive functioning after subarachnoid haemorrhage of unknown origin. Acta Neurol Scand 1989;80(05):400-410

6 Fisher CM, Kistler JP, Davis JM. Relation of cerebral vasospasm to subarachnoid hemorrhage visualized by computerized tomographic scanning. Neurosurgery 1980;6(01):1-9

7 Hijdra A, van Gijn J, Nagelkerke NJ, Vermeulen M, van Crevel H. Prediction of delayed cerebral ischemia, rebleeding, and outcome after aneurysmal subarachnoid hemorrhage. Stroke 1988;19(10): 1250-1256

8 Claassen J, Bernardini GL, Kreiter K, et al. Effect of cisternal and ventricular blood on risk of delayed cerebral ischemia after subarachnoid hemorrhage: the Fisher scale revisited. Stroke 2001;32(09):2012-2020

9 Macdonald RL, Rosengart A, Huo D, Karrison T. Factors associated with the development of vasospasm after planned surgical treatment of aneurysmal subarachnoid hemorrhage. J Neurosurg 2003;99(04):644-652

10 Fujita S. Computed tomographic grading with Hounsfield number related to delayed vasospasm in cases of ruptured cerebral aneurysm. Neurosurgery 1985;17(04):609-612
11 Reilly C, Amidei C, Tolentino J, Jahromi BS, Macdonald RL. Clot volume and clearance rate as independent predictors of vasospasm after aneurysmal subarachnoid hemorrhage. J Neurosurg 2004;101(02):255-261

12 Frontera JA, Claassen J, Schmidt JM, et al. Prediction of symptomatic vasospasm after subarachnoid hemorrhage: the modified fisher scale. Neurosurgery 2006;59(01):21-27, discussion 21-27

13 Kramer AH, Hehir M, Nathan B, et al. A comparison of 3 radiographic scales for the prediction of delayed ischemia and prognosis following subarachnoid hemorrhage. J Neurosurg 2008;109 (02):199-207

14 Lantigua H, Ortega-Gutierrez S, Schmidt JM, et al. Subarachnoid hemorrhage: who dies, and why? Crit Care 2015;19(01):309

15 Zhao B, Yang H, Zheng K, et al; AMPAS study group. Predictors of good functional outcomes and mortality in patients with severe rebleeding after aneurysmal subarachnoid hemorrhage. Clin Neurol Neurosurg 2016;144:28-32

16 Kassell NF, Sasaki T, Colohan AR, Nazar G. Cerebral vasospasm following aneurysmal subarachnoid hemorrhage. Stroke 1985;16 (04):562-572

17 Hütter BO, Kreitschmann-Andermahr I, Gilsbach JM. Healthrelated quality of life after aneurysmal subarachnoid hemorrhage: impacts of bleeding severity, computerized tomography findings, surgery, vasospasm, and neurological grade. J Neurosurg 2001;94(02):241-251

18 Klimo P Jr, Kestle JR, MacDonald JD, Schmidt RH. Marked reduction of cerebral vasospasm with lumbar drainage of cerebrospinal fluid after subarachnoid hemorrhage. J Neurosurg 2004;100(02): 215-224

19 Ko SB, Choi HA, Helbok R, et al. Quantitative analysis of hemorrhage clearance and delayed cerebral ischemia after subarachnoid hemorrhage. J Neurointerv Surg 2016;8(09):923-926

20 Jones J, Sayre J, Chang R, et al. Cerebral vasospasm patterns following aneurysmal subarachnoid hemorrhage: an angiographic study comparing coils with clips. J Neurointerv Surg 2015;7 (11):803-807

21 Stienen MN, Smoll NR, Weisshaupt R, et al. Delayed cerebral ischemia predicts neurocognitive impairment following aneurysmal subarachnoid hemorrhage. World Neurosurg 2014;82(05): e599-e605

22 Kreiter KT, Copeland D, Bernardini GL, et al. Predictors of cognitive dysfunction after subarachnoid hemorrhage. Stroke 2002;33(01): 200-208

23 Hijdra A, Brouwers PJ, Vermeulen M, van Gijn J. Grading the amount of blood on computed tomograms after subarachnoid hemorrhage. Stroke 1990;21(08):1156-1161

24 Caeiro L, Santos CO, Ferro JM, Figueira ML. Neuropsychiatric disturbances in acute subarachnoid haemorrhage. Eur J Neurol 2011;18(06):857-864

25 Hütter BO, Kreitschmann-Andermahr I, Gilsbach JM. Cognitive deficits in the acute stage after subarachnoid hemorrhage. Neurosurgery 1998;43(05):1054-1065

26 Yoo SD, Kim DH, Kim GK, Bark J. Characteristics of computerized neuropsychologic test according to the location of aneurysmal subarachnoid hemorrhage. Ann Rehabil Med 2011;35(05): 680-686

27 Wong GK, Lam S, Ngai K, Wong A, Mok V, Poon WS; Cognitive Dysfunction after Aneurysmal Subarachnoid Haemorrhage Investigators. Evaluation of cognitive impairment by the Montreal cognitive assessment in patients with aneurysmal subarachnoid haemorrhage: prevalence, risk factors and correlations with 3 month outcomes. J Neurol Neurosurg Psychiatry 2012;83(11): 1112-1117

28 Sheldon S, Macdonald RL, Cusimano M, Spears J, Schweizer TA. Long-term consequences of subarachnoid hemorrhage: examining working memory. J Neurol Sci 2013;332(1-2):145-147 
29 Krajewski K, Dombek S, Martens T, Köppen J, Westphal M, Regelsberger J. Neuropsychological assessments in patients with aneurysmal subarachnoid hemorrhage, perimesencephalic SAH, and incidental aneurysms. Neurosurg Rev 2014;37(01): 55-62

30 Wallmark S, Lundström E, Wikström J, Ronne-Engström E. Attention deficits after aneurysmal subarachnoid hemorrhage mea- sured using the test of variables of attention. Stroke $2015 ; 46(05)$ : 1374-1376

31 de Souza ML, Vieira AÇ, Andrade G, Quinino S, de Fátima Leal Griz M, Azevedo-Filho HR. Fisher grading scale associated with language disorders in patients with anterior circulation aneurysmal subarachnoid hemorrhage. World Neurosurg 2015;84 (02):308-313 